\title{
Ferromagnetic behaviour of $\mathrm{ZnO}$ : the role of grain boundaries
}

\author{
Boris B. Straumal ${ }^{\star 1}, 2,3,4$, Svetlana G. Protasova ${ }^{2,3}$, Andrei A. Mazilkin ${ }^{1,2}$, \\ Eberhard Goering $^{3}$, Gisela Schütz ${ }^{3}$, Petr B. Straumal ${ }^{4,5}$ and Brigitte Baretzky ${ }^{1}$
}

\begin{tabular}{|c|c|}
\hline Review & Open Access \\
\hline Address: & Beilstein J. Nanotechnol. 2016, 7, 1936-1947. \\
\hline $\begin{array}{l}\text { Karlsruher Institut für Technologie, Institut für Nanotechnologie, } \\
\text { Hermann-von-Helmholtz-Platz 1, } 76344 \text { Eggenstein-Leopoldshafen, }\end{array}$ & doi:10.3762/bjnano.7.185 \\
\hline Germany, ${ }^{2}$ Institute of Solid State Physics, Russian Academy of & Received: 24 August 2016 \\
\hline Sciences, Ac. Ossipyan str. 2, 142432 Chernogolovka, Russia, & Accepted: 09 November 2016 \\
\hline $\begin{array}{l}{ }^{3} \text { Max-Planck-Institut für Intelligente Systeme, Heisenbergstrasse 3, } \\
70569 \text { Stuttgart, Germany, }{ }^{4} \text { National University for Research and }\end{array}$ & Published: 07 December 2016 \\
\hline $\begin{array}{l}\text { Technology "MISiS", Leninsky prospect 4, } 119991 \text { Moscow, Russia } \\
\text { and } 5 \text { Institute of Metallurgy and Materials Science, Russian Academy } \\
\text { of Sciences, Leninsky prospect 49, } 117991 \text { Moscow, Russia }\end{array}$ & $\begin{array}{l}\text { This article is part of the Thematic Series "Advances in nanomaterials II" } \\
\text { and is dedicated to Professor Herbert Gleiter, a significant contributor to } \\
\text { modern knowledge of structure, physics and chemistry of grain } \\
\text { boundaries, on the occasion of his 75th anniversary. }\end{array}$ \\
\hline \multicolumn{2}{|l|}{ Email: } \\
\hline Boris B. Straumal ${ }^{*}$ - straumal@mf.mpg.de & Guest Editor: H. Hahn \\
\hline * Corresponding author & $\begin{array}{l}\text { (c) } 2016 \text { Straumal et al.; licensee Beilstein-Institut. } \\
\text { License and terms: see end of document. }\end{array}$ \\
\hline $\begin{array}{l}\text { Keywords: } \\
\text { ferromagnetism; grain boundaries; zinc(II) oxide ( } \mathrm{ZnO})\end{array}$ & \\
\hline
\end{tabular}

\begin{abstract}
The possibility to attain ferromagnetic properties in transparent semiconductor oxides such as $\mathrm{ZnO}$ is very promising for future spintronic applications. We demonstrate in this review that ferromagnetism is not an intrinsic property of the ZnO crystalline lattice but is that of $\mathrm{ZnO} / \mathrm{ZnO}$ grain boundaries. If a $\mathrm{ZnO}$ polycrystal contains enough grain boundaries, it can transform into the ferromagnetic state even without doping with "magnetic atoms" such as Mn, Co, Fe or Ni. However, such doping facilitates the appearance of ferromagnetism in $\mathrm{ZnO}$. It increases the saturation magnetisation and decreases the critical amount of grain boundaries needed for FM. A drastic increase of the total solubility of dopants in $\mathrm{ZnO}$ with decreasing grain size has been also observed. It is explained by the multilayer grain boundary segregation.
\end{abstract}

\section{Review \\ Introduction}

In 2000 the seminal work of Tomasz Dietl et al. appeared [1]. In this work it was predicted theoretically that many semiconductor oxides can become ferromagnetic (FM) if one dopes them with "magnetic" atoms such as iron, manganese and cobalt. Other theoreticians published in that time similar works [2]. It has been predicted that the Curie temperature of such diluted doped magnetic semiconductor oxides can be quite high, even above room temperature. Especially promising was zinc oxide. According to Dietl, $\mathrm{ZnO}$ should possess the highest Curie temperature [1]. 
Of course, such a prediction could not be ignored by experimentalists in the field of semiconductors, because the possibility to make a transparent broadband semiconductor, such as $\mathrm{ZnO}$, ferromagnetic is very promising for future spintronic applications. The ferromagnetism (FM) opens a way to change the optical and/or electrical properties of such a material by applying an external (permanent or alternating) magnetic field. And vice versa, by applying an external (permanent or alternating) electric field one could influence the magnetic behaviour of such a material. Especially attractive is that zinc oxide is cheap. It is widely used for various applications from sunblock creams to varistors for power electronics $[3,4]$. The various technologies of deposition of pure and doped $\mathrm{ZnO}$ films, sintering of $\mathrm{ZnO}$ ceramics and growth of single crystals, are well known and well elaborated. It seemed that nothing could prevent the success of the synthesis of ferromagnetic $\mathrm{ZnO}$ doped by iron, manganese, cobalt, or other "magnetic" atoms. Indeed first successes came soon. Ferromagnetic $\mathrm{ZnO}$ films were synthesised by pulsed laser deposition (PLD), or magnetron sputtering [5-9]. However, the first disappointments also appeared immediately. Namely, single crystals, ceramics sintered from coarse-grained powders and single-crystalline films deposited by molecular beam epitaxy (MBE) were never ferromagnetic. Other synthesis technologies such as wet-chemistry methods or chemical vapour deposition (CVD) sometimes yielded ferromagnetic $\mathrm{ZnO}$ and sometimes they did not.

It was of course a challenge for solid-state physics and materials science to explain such strange behaviour and to develop the methods to predict (at least qualitatively) where and when the ferromagnetism appears in zinc oxide. We supposed that ferromagnetic behaviour of pure and doped $\mathrm{ZnO}$ is controlled by grain boundaries (GBs) and appears only if the grain boundary network (the "ferromagnetic foam") is dense enough [7]. Our first results concerning the role of grain boundaries in the ferromagnetic behaviour of pure $\mathrm{ZnO}$ and $\mathrm{ZnO}$ doped by $\mathrm{Mn}$ and $\mathrm{Co}$ as well as concerning the dependence of the solubility of $\mathrm{Mn}$ and $\mathrm{Co}$ in $\mathrm{ZnO}$ on the grain size were published in two reviews $[10,11]$ summarizing the essential findings obtained at that time. Later, the hypothesis about the role of GB in ferromagnetic behaviour was supported by our new results on $\mathrm{ZnO}$ doped with nickel and iron $[6,9,12]$ as well as by measurements with lowenergy muon spin relaxation combined with molecular dynamics modeling and density functional theory calculations [13] These new results constitute the additional contribution of the current review. It aims to give the comprehensive and updated view on the GB contribution to the ferromagnetic behaviour of $\mathrm{ZnO}$ as well as on the multilayer GB adsorption drastically increasing the overall dopant solubility in $\mathrm{ZnO}$. This review is also a modest tribute to the 75th anniversary of Professor Herbert Gleiter who contributed so much to the development of our knowledge of structure, physics and chemistry of grain boundaries.

\section{Critical grain size for the ferromagnetic behaviour of $\mathrm{ZnO}$}

First of all we analysed the whole corpus of published data on ferromagnetic behaviour of zinc oxide and developed our own method for the synthesis of pure and doped nanocrystalline $\mathrm{ZnO}$ films. The obtained data are summarized in Figure 1 for pure $\mathrm{ZnO}$ and $\mathrm{ZnO}$ doped with manganese, cobalt, iron and nickel [6-9]. The full list of used references can be found in [6-9]. In each of the five parts of Figure 1 the temperature is plotted along the vertical axis. It is either the synthesis temperature or the temperature of last annealing of the oxides. The grain boundary specific area $s_{\mathrm{GB}}$ is given in the horizontal axis. $s_{\mathrm{GB}}$ is the area of GBs in a unit volume. We added an experimental point to the diagrams in Figure 1 if it was possible to estimate from the published experimental work (a) the grain size, (b) the grain shape - equiaxial, elongated or flattened - and (c) porosity of sample, i.e., the portion of grain boundaries and free surfaces. When possible, we tried also to take into account the so-called grain boundary character [14]. In other words we tried to include the high-angle grain boundaries and to exclude the low-angle ones [15]. It is easy to calculate $s_{\mathrm{GB}}$ if the grains are equiaxial (circles in Figure 1).

The optimal space-filling grain shape for such polycrystals with a minimal surface area is the tetrakaidecahedron, a polyhedron with 14 faces. Thus, the GB-area-to-volume ratio is $s_{\mathrm{GB}}=$ $1.65 / D$, where $D$ is the mean grain size [16]. If the grains were elongated or flattened, the aspect ratio was taken in the account, and $s_{\mathrm{GB}}$ was modified accordingly (triangles in Figure 1). The equation for $s_{\mathrm{GB}}$ from [16] is true if a sample is dense and does not contain any pores. In case of porous samples (like for example for partially sintered powders or nanowires, diamonds and downward triangles in Figure 1) the value of $s_{\mathrm{GB}}$ was multiplied by the porosity factor $p<1$. In the upper horizontal axis the values of grain size are given as recalculated from $s_{\mathrm{GB}}$ supposing that the sample is dense and the grains are equiaxial. Squares correspond to the single crystalline samples. They do not contain any GBs, therefore, we put them in the diagram at grain size of $10^{-1} \mathrm{~m}$. Filled symbols in Figure 1 show the data where the $\mathrm{ZnO}$ samples were ferromagnetic. Open symbols correspond to the samples for which no FM behaviour has been observed.

Large filled circles show our own experimental data obtained using $\mathrm{ZnO}$ films synthesized using the original "liquid ceramics" method. This is a kind of so-called wet-chemistry methods for the synthesis of nanograined oxide films. The precursor was zinc(II) butanoate dissolved in an organic solvent. It 

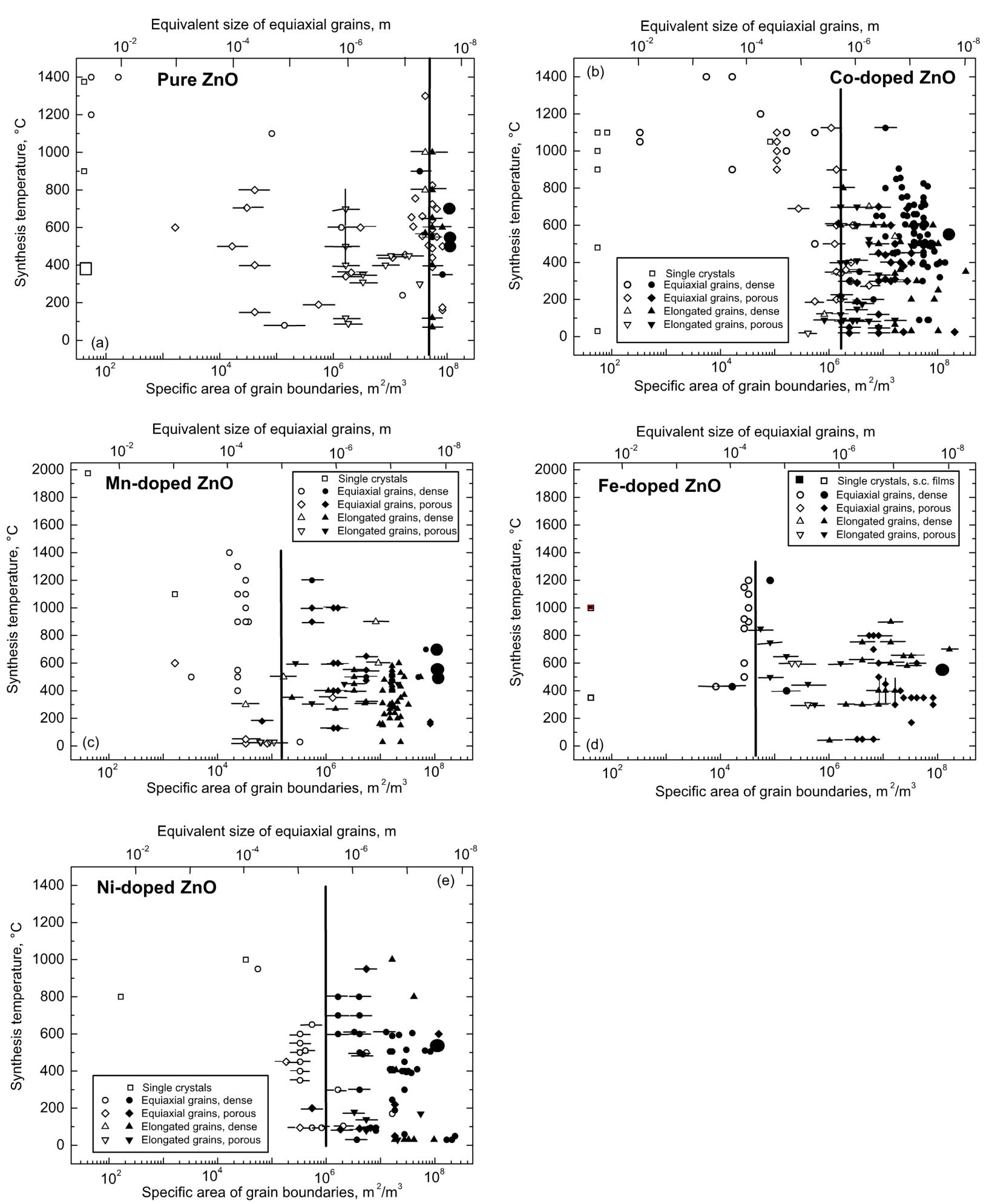

Figure 1: Ferromagnetic (full symbols) and paramagnetic or diamagnetic properties (open symbols) of (a) pure zinc oxide [7] and ZnO doped with (b) cobalt [8], (c) manganese [7], (d) iron [9] and (e) nickel [6] versus the specific area of grain boundaries $s_{\mathrm{GB}}$ (ratio of the area of the boundaries to the volume) at various synthesis temperatures $T$. In the upper horizontal axis the values of grain size are given as recalculated from $s_{\mathrm{GB}}$ supposing that the sample is dense and grains are equiaxial. Vertical lines mark the threshold values of $s_{\text {th }}$ dividing FM (right) and non-FM behaviour of $Z$ nO. Large symbols correspond to the experimental data obtained in the works [6-9]. Figure was replotted basing on the plots reproduced with permission from [6-9], copyright Institute of Problems of Mechanical Engineering, Russian Academy of Sciences (PME RAS, "Advanced Study Center" Co. Ltd), American Physical Society and Taylor \& Francis. 
was used for the preparation of pure zinc oxide. Similar solutions of $\mathrm{Mn}, \mathrm{Co}, \mathrm{Ni}$ and $\mathrm{Fe}$ butanoates of were also prepared. The Zn precursor was mixed, respectively, with $\mathrm{Mn}, \mathrm{Co}, \mathrm{Ni}$ or Fe butanoates in appropriate proportions (in order to obtain doped $\mathrm{ZnO}$ with dopant contents from 0.1 to 50 atom \%). The mixture of liquid precursors was deposited on a substrate (aluminium polycrystalline foil or sapphire single crystalline plate). Then the deposited liquid mixture was dried at $150{ }^{\circ} \mathrm{C}$. After drying the pyrolysis took place in argon or in air at temperatures between 500 and $600{ }^{\circ} \mathrm{C}$. The resulted pure and doped $\mathrm{ZnO}$ films of thicknesses between 50 and $200 \mathrm{~nm}$ (measured by electron-probe X-ray microanalysis and transmission electron microscopy) were dense (i.e., pore free) and contained equiaxial grains with sizes of about $20 \mathrm{~nm}$ (Figure 2). The films were transparent and slightly greenish.

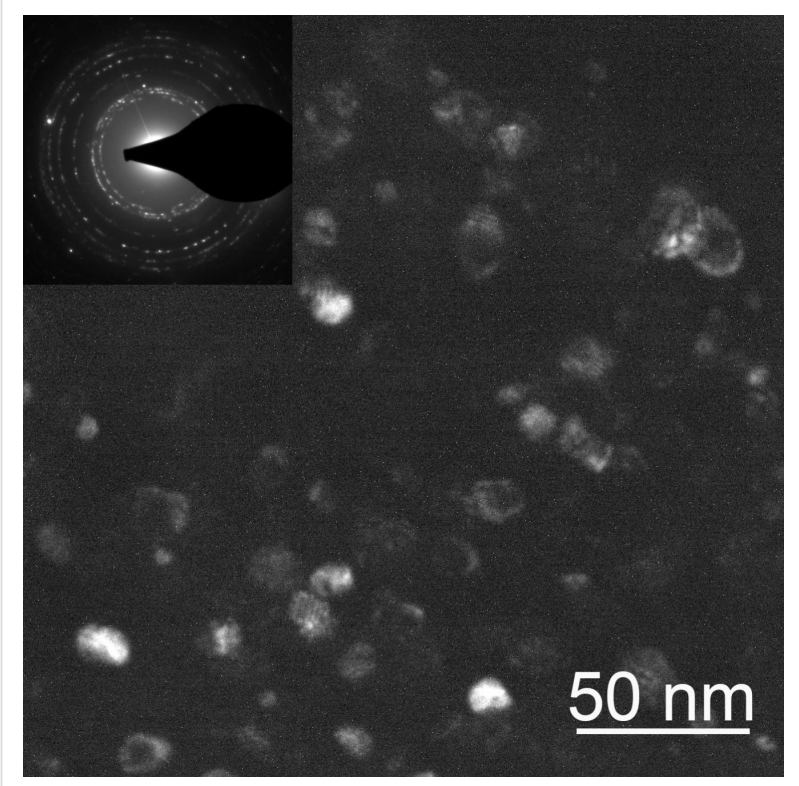

Figure 2: Dark-field TEM micrograph of a thin zinc oxide nanocrystalline film obtained using the liquid-ceramics method.

The composition of the films was controlled by atomic absorption spectroscopy in a Perkin-Elmer spectrometer and by electron-probe X-ray microanalysis with a Tescan Vega TS5130 MM scanning electron microscope (SEM) equipped by energy dispersive X-ray spectrometer (Oxford Instruments). TEM studies were performed using JEM-4000FX microscope at an accelerating voltage of $400 \mathrm{kV}$. X-ray diffraction (XRD) was studied using a Siemens diffractometer with a graphite monochromator and a gas flow detector using $\mathrm{Fe} \mathrm{K} \alpha$ radiation. The grain size in pure and doped $\mathrm{ZnO}$ was measured by TEM and additionally by XRD. It was calculated from the angular dependence of the line broadening [17]. The magnetic properties were measured using a SQUID interferometer (Quantum Design
MPMS-7 and MPMS-XL) in the external magnetic field applied parallel to the sample plane. The diamagnetic signal from a sample holder and a substrate was accurately subtracted from the magnetization curves.

In Figure 3 the magnetization curves are plotted for pure $\mathrm{ZnO}$ and $\mathrm{ZnO}$-doped with 0.1 and 10 atom \% Mn [7]. All three curves demonstrated typical ferromagnetic behaviour with saturation (the saturation magnetization $J_{\mathrm{s}}$ is, respectively, $1 \times 10^{-3} \mu \mathrm{B} /$ f.u. $=0.06 \mathrm{emu} / \mathrm{g}, 2 \times 10^{-3} \mu \mathrm{B} /$ f.u. $=0.16 \mathrm{emu} / \mathrm{g}$, and $0.8 \times 10^{-3} \mu \mathrm{B} /$ f.u. $=0.04 \mathrm{emu} / \mathrm{g}$ ) and hysteresis with a coercive force $H_{\mathrm{c}}$ of about $0.01-0.02 \mathrm{~T}$ (see insets in Figure 4). All three samples have grain sizes well below the barrier value (Figure 2) leading to the FM behaviour. $J_{\mathrm{s}}$ increases linearly with the increasing thickness of the $\mathrm{ZnO}$ film (Figure 4). The temperature dependence of $J_{\mathrm{s}}$ permits to estimate the Curie temperature $T_{\mathrm{C}}$. At room temperature the saturation magnetization of pure zinc oxide films was only $40 \%$ lower than $J_{\mathrm{s}}$ measured at $40 \mathrm{~K}$ [7]. It means that $T_{\mathrm{C}}$ of our films is much higher than the room temperature. The main feature of all five plots in Figure 1 is that $\mathrm{ZnO}$ becomes ferromagnetic only if $s_{\mathrm{GB}}$ exceeds a certain critical value $s_{\text {th }}$. In other words, FM properties appear if the grains are small enough. Moreover, one needs grain boundaries. If the $\mathrm{ZnO}$ powders are fine- or even nanograined, but not sintered (i.e., $p<<1$ ), they have few GBs. Then they are not ferromagnetic and, as a result, appear in the left part of a diagram.

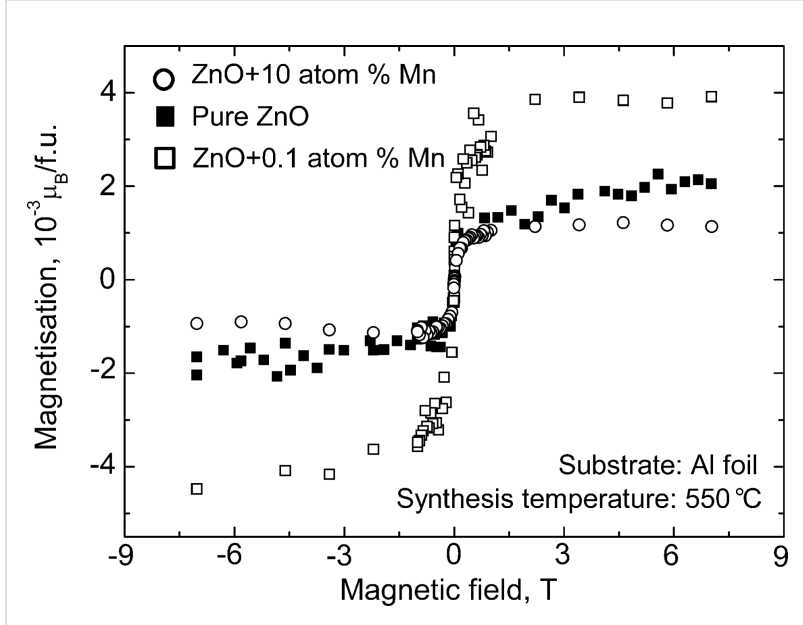

Figure 3: Magnetization $J_{\mathrm{S}}$ (in units of $10^{-3} \mu \mathrm{B} / \mathrm{f}$.u.) as a function of the applied external magnetic field for pure zinc oxide films and zinc oxide films doped with 0.1 and 10 atom \% Mn at room temperature. Reproduced with permission from [7], copyright 2009 American Physical Society.

From Figure 1 follow two important contradictions with the seminal prediction of T. Dietl [1]: (1) bulk ZnO, even doped with "magnetic" atoms, is not ferromagnetic; (2) even undoped 


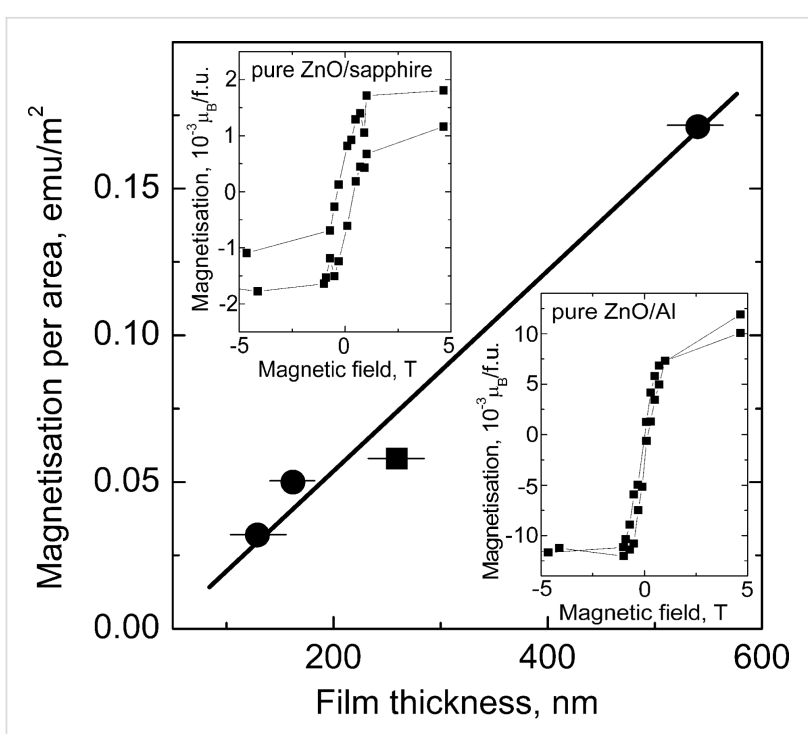

Figure 4: Dependence of magnetization per area unit (calibrated in $\mathrm{emu} / \mathrm{m}^{2}$ ) on the film thickness (circles are pure zinc oxide, square is for $\mathrm{ZnO}$ doped by 10 atom \% Mn) measured at room temperature. Insets show magnetic hysteresis for pure $\mathrm{ZnO}$ deposited on the sapphire single crystal (left) and on the aluminium polycrystal (right). Reproduced with permission from [7], copyright 2009 American Physical Society.

pure $\mathrm{ZnO}$ can become ferromagnetic if it contains enough grain boundaries. Indeed, pure $\mathrm{ZnO}$ possesses ferromagnetic properties at $s_{\mathrm{GB}}>s_{\mathrm{th}}=5.3 \times 10^{7} \mathrm{~m}^{2} / \mathrm{m}^{3}$ [7], in other words at grain sizes below $20 \mathrm{~nm}$ (Figure 1a). However, the addition of manganese, cobalt, iron and nickel positively influences the FM of $\mathrm{ZnO}$ polycrystals. Such additions decrease the amount of GBs needed for FM behaviour. This fact somehow coincides with the prediction of Dietl et al. [1]. For example, in a number of works where $s_{\mathrm{GB}}$ fell between $s_{\text {th }}$ for pure and manganesedoped $\mathrm{ZnO}$, paramagnetic properties were observed in pure zinc oxide and ferromagnetic properties in manganese-doped samples $[18,19]$. As a result, $s_{\text {th }}$ increases with doping starting from pure $\mathrm{ZnO}$. The following $s_{\text {th }}$ values for different dopants have been observed: pure $\mathrm{ZnO} s_{\text {th }}=5.3 \times 10^{7} \mathrm{~m}^{2} / \mathrm{m}^{3}$ [7], cobaltdoped $\mathrm{ZnO}, s_{\text {th }}=1.5 \times 10^{6} \mathrm{~m}^{2} / \mathrm{m}^{3}$ [8], manganese-doped $\mathrm{ZnO}, s_{\text {th }}=2.4 \times 10^{5} \mathrm{~m}^{2} / \mathrm{m}^{3}$ [7], nickel-doped $\mathrm{ZnO}$, is $s_{\text {th }}=$ $1.0 \times 10^{6} \mathrm{~m}^{2} / \mathrm{m}^{3}[6]$ and iron-doped $\mathrm{ZnO}, s_{\text {th }}=5 \times 10^{4} \mathrm{~m}^{2} / \mathrm{m}^{3}$ [9]. Thus, iron most actively promotes the FM behaviour of zinc oxide. $\mathrm{ZnO}$ polycrystals doped with Fe become ferromagnetic already at an effective grain size of about $40 \mu \mathrm{m}$.

\section{Direct evidence of grain boundary influence on the ferromagnetic behaviour of $\mathrm{ZnO}$}

Figure 1 shows the correlation between grain size (or specific density $s_{\mathrm{GB}}$ of grain boundaries in the volume unit) and the presence or absence of ferromagnetic behaviour in $\mathrm{ZnO}$. These plots are based on the data collected from hundreds independent investigations and show that FM appears only above a certain critical value $s_{\text {th }}$ of the GB specific density $s_{\mathrm{GB}}$. This is impressive evidence that GBs are the key to FM in $\mathrm{ZnO}$. However, this evidence is indirect. Can we find the method that would be able to give us the direct and unambiguous evidence that ferromagnetic properties in $\mathrm{ZnO}$ derives from GBs?

Such direct evidence can be obtained from the local-probe method of low-energy muon spin relaxation (LE- $\mu \mathrm{SR}$ ) [13]. This method is based on the idea to implant spin-polarized lowenergy positive muons into $\mathrm{ZnO}$. Due to their positive charge, the low-energy muons are trapped in the interstitial lattice sites. The motion of the muon spin is due to the magnetic field experienced by the muon. Therefore, low-energy muons act as highly sensitive probes of magnetic fields originating from magnetic moments in their close proximity and can provide information on the local environment of the muonin a very similar way to other magnetic resonance techniques. More details on the $\mu$ SR method can be found in $[20,21]$.

Low-energy muon spin relaxation measurements were carried out at the $\mu$ E4 Low-Energy Muon (LEM) beamline at the Swiss Muon Source $(\mathrm{S} \mu \mathrm{S})$, Paul Scherrer Institute, Switzerland $[22,23]$. During these measurements the positive muons were implanted into the films. The positive muons were $100 \%$ spin polarized. The spin polarization was parallel to the sample surface. The measurements were done in zero field at different temperatures of $-223,-103$, and $23{ }^{\circ} \mathrm{C}$. Different sample implantation depths were also used (10 to $75 \mathrm{~nm}$ ). No dependence on temperature or penetration depth was observed. Therefore, the $\mu$ SR spectra were obtained by averaging the data obtained at different temperatures and different sample penetration depths in order to improve the signal to noise ratio.

Three different samples were investigated with different values of $s_{\mathrm{GB}}$. One sample was single crystalline (purchased from the Mateck Company, Germany) and contained, therefore, no GBs. The second sample (coarse-grained or CG) had a grain size of $65 \mathrm{~nm}$ and $s_{\mathrm{GB}}=2.65 \cdot 10^{7} \mathrm{~m}^{2} / \mathrm{m}^{3}$. The third sample (fine grained or FG) had small grains with a size of $31 \mathrm{~nm}$ and $s_{\mathrm{GB}}=$ $5.32 \cdot 10^{7} \mathrm{~m}^{2} / \mathrm{m}^{3}$. These $s_{\mathrm{GB}}$ values are, respectively, slightly below and above the threshold value $s_{\text {th }}=5.3 \times 10^{7} \mathrm{~m}^{2} / \mathrm{m}^{3}$ for pure $\mathrm{ZnO}$ (Figure 1a and [7]). The magnetic measurements supported the choice of three specimens. Namely, the single crystal showed only a negligibly small saturation magnetization of $2 \times 10^{-4} \mathrm{emu} / \mathrm{cm}^{3}$ [13]. The CG sample was weakly ferromagnetic with $J_{\mathrm{s}}=1.25 \mathrm{emu} / \mathrm{cm}^{3}$ [13]. The FG sample with the smallest grains had the highest saturation magnetization of $J_{\mathrm{s}}=8.3 \cdot \mathrm{emu} / \mathrm{cm}^{3}$. The $J_{\mathrm{s}}$ values measured at $50 \mathrm{~K}$ and RT were very similar (like in [7]). This fact is an important indicator for true ferromagnetism in $\mathrm{ZnO}$ and a high Curie temperature $T_{\mathrm{C}}$ [13]. 
When using LE- $\mu$ SR the spin relaxation of muons in zero field (ZF- $\mu \mathrm{SR})$ is measured. It shows the dephasing of muons and permits to determine the corresponding decay in the muon asymmetry spectrum [24]. As a result the decay in the muon asymmetry spectrum can be obtained. Such decay is due to the presence of an internal magnetic field distribution. In Figure 5 one can see three such time-dependent spectra of $\mu \mathrm{SR}$ asymmetry for the three studied samples with different GB specific density. In Figure 5 we plotted the normalized asymmetry. The experimental points have broad scatter and were fitted using the program Musrfit [25]. A measure for the fraction of magnetic volume in a sample is given by the relaxing amplitude of the asymmetry. The strongest relaxation is observed for the $\mathrm{ZnO}$ films with smallest grains (lower curve, open squares). It corresponds to a total magnetic volume fraction of about $35 \%$. The lowest relaxation is observed for the $\mathrm{ZnO}$ single crystal (upper curve, open circles). The non-magnetic single crystal has no significant magnetic volume fraction at all. In the middle lies the curve for coarse-grained $\mathrm{ZnO}$ (filled squares). The magnetic volume fraction for this $\mathrm{ZnO}$ film was about $15 \%$. Using the local-probe method of low-energy muon spin relaxation measurements we obtained the expected direct evidence that ferromagnetic behaviour of $\mathrm{ZnO}$ is due to the atoms located in $\mathrm{ZnO}$ grain boundaries and not in the bulk [13].

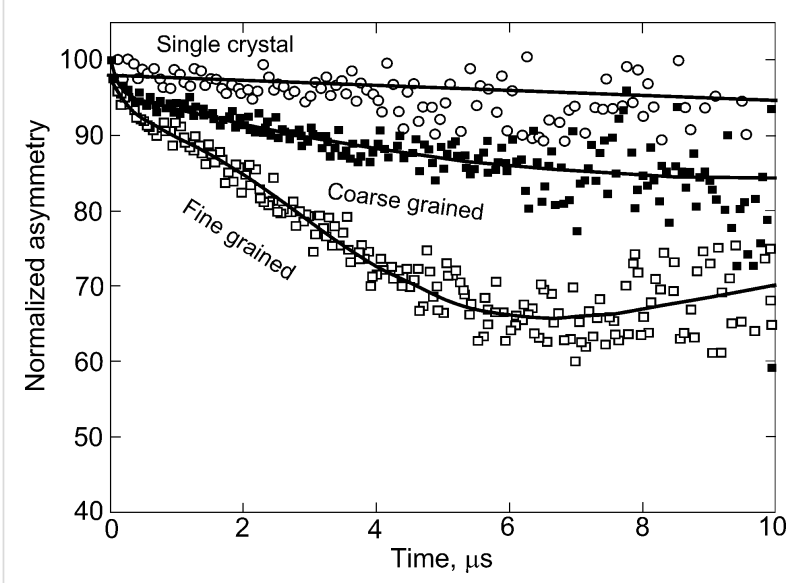

Figure 5: Averaged zero-field $\mu$ SR spectra for the single crystal (top curve, open circles), the coarse grained (middle curve, filled squares), and the fine grained (bottom curve, open squares) $\mathrm{ZnO}$ samples. Replotted with permission from [13], copyright 2015 Nature Publishing Group.

The LE- $\mu$ SR measurements were supported by theoretical studies [13]. Using molecular dynamics the simulations of 4800 atoms in a periodic box were performed for two grain boundaries. They permitted to simulate the atomic disorder in the grain boundary region. The simulation periodic box was first equilibrated at $300 \mathrm{~K}$ and constant pressure of $10^{5} \mathrm{~Pa}$ for $0.5 \mathrm{~ns}$, then heated to $2700 \mathrm{~K}$ and equilibrated for $1 \mathrm{~ns}$. Then it was cooled to $300 \mathrm{~K}$ and equilibrated for $1 \mathrm{~ns}$. The atomic configurations in GBs obtained by the molecular dynamics formed the basis for the further density functional theory calculations. For the cluster with about 200 atoms in an effective electrostatic field formed by the rest of the simulated system the electronic structure was determined. The calculation show that for single-crystalline $\mathrm{ZnO}$ the energy difference between highest occupied molecular orbital (HOMO) and lowest unoccupied molecular orbital (LUMO) is quite high and reaches about $4 \mathrm{eV}$. However, this difference for the sample containing the disordered GB area diminishes almost to zero. Moreover, energy of the lowest magnetic triplet state for GB is only $0.2 \mathrm{eV}$ higher than the closed shell ground state. Both these results permit us to conclude that unpaired electrons can exist in GBs and atomic configurations may exist where such electrons are coupled ferromagnetically [13].

\section{Influence of dopant concentration on the ferromagnetic behaviour of $\mathrm{ZnO}$}

In Figure 1b-e the data on presence or absence of ferromagnetic behaviour are given in dependence on the grain size for pure $\mathrm{ZnO}$ and $\mathrm{ZnO}$ doped with different atoms. However, they are given without taking in account how much manganese, cobalt, iron and nickel is in $\mathrm{ZnO}$. How does the concentration of these elements influence the magnetisation of $\mathrm{ZnO}$ ? We tried to answer this question using doped $\mathrm{ZnO}$ films synthesised using the liquid ceramics technology. Figure 6 shows the concentration dependences of the saturation magnetisation $J_{\mathrm{s}}$ for such $\mathrm{ZnO}$ films doped with manganese [26], cobalt [8], or iron [9].

In all three cases the $J_{\mathrm{s}}$ value strongly increases (about 4 to 20 times) when small fractions (0.02-0.12 atom \%) of Co, Mn or Fe are added to pure $\mathrm{ZnO}$. Around 0.5 atom \% of $\mathrm{Co}$, Mn or Fe the saturation magnetization reaches maximum and then decreases again down to the value close to that of pure $\mathrm{ZnO}$ or even less. Thus, the addition of small amount of "magnetic atoms" indeed makes $\mathrm{ZnO}$ "more ferromanetic" as predicted by Dietl et al. [1]. However, above a dopant concentration of $5-10$ atom $\%$ the behaviour of $J_{\mathrm{s}}$ is different for $\mathrm{Co}, \mathrm{Mn}$ and $\mathrm{Fe}$. In the case of cobalt (Figure 6a), the $J_{\mathrm{s}}(c)$ curve has only one maximum, and $J_{\mathrm{s}}$ remains low up to the solubility limit of Co in $\mathrm{ZnO}$ (shown by the vertical dotted line at 32 atom \% Co). In the case of iron (Figure $6 \mathrm{c}$ ), $J_{\mathrm{s}}$ increases again above solubility limit of $\mathrm{Fe}$ in $\mathrm{ZnO}$ (shown by the vertical dotted line at 18 atom \% $\mathrm{Fe}$ ) and the $J_{\mathrm{s}}(c)$ curve has two maxima. In the case of manganese (Figure 6b), $J_{\mathrm{s}}$ strongly increases again above 5 atom $\% \mathrm{Mn}$, reaches a maximum close to the solubility limit of $\mathrm{Mn}$ in $\mathrm{ZnO}$ (shown by the vertical dotted line at 26 atom \% $\mathrm{Mn})$ and decreases for the second time down to the value for pure $\mathrm{ZnO}$ or less above the solubility limit of $\mathrm{Mn}$ in $\mathrm{ZnO}$. Thus, the $J_{\mathrm{s}}(c)$ curve has two maxima and two minima. 

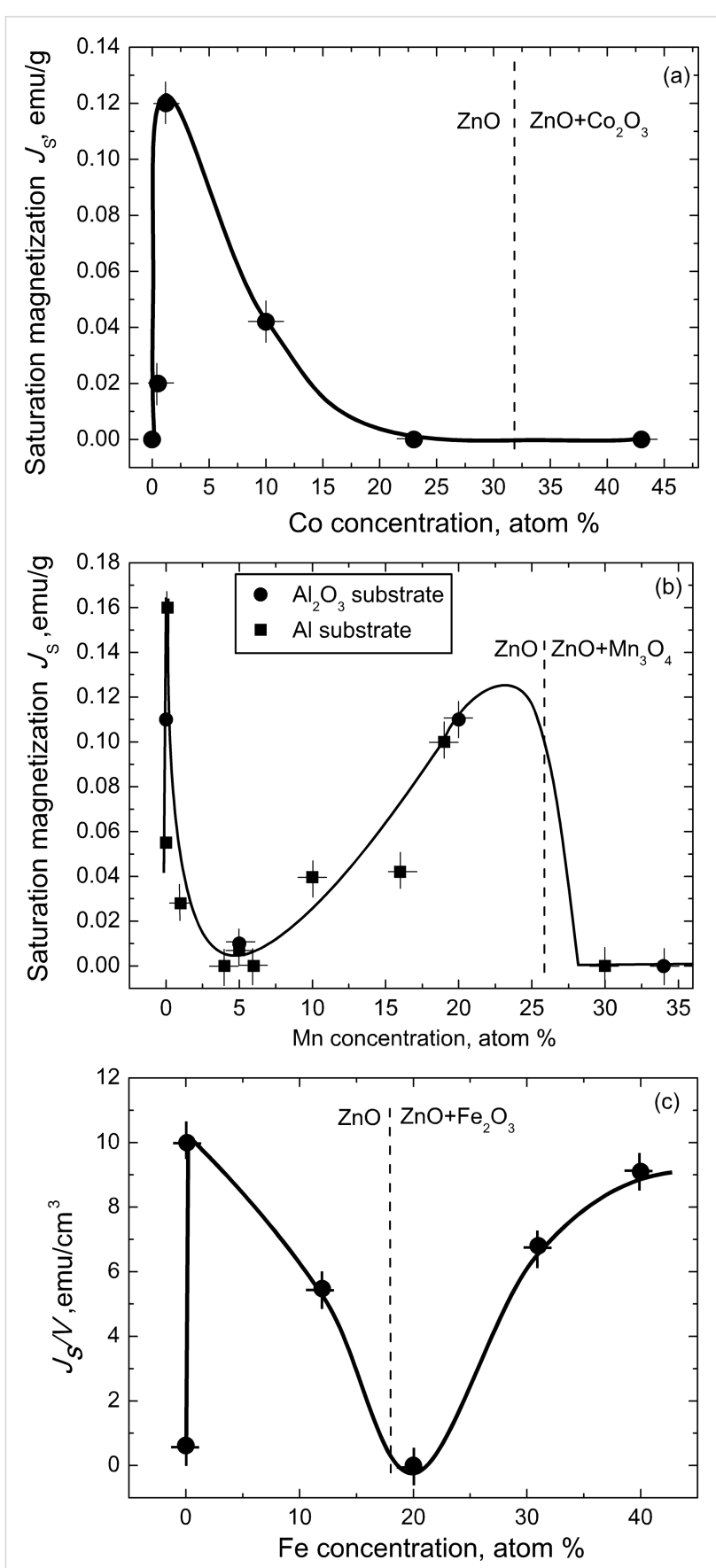

Figure 6: Saturation magnetization of doped zinc oxide films versus the concentration of (a) cobalt [8], (b) manganese [26], and (c) iron [9]. Figure was replotted based on the figures from $[8,9,26]$ with permission, copyright Taylor \& Francis and AIP Publishing

How we can explain the different number of maxima and minima in Figure 6? Remember that manganese can possess three different oxidation states in $\mathrm{ZnO}$, namely $\mathrm{Mn}^{2+}, \mathrm{Mn}^{3+}$, and $\mathrm{Mn}^{4+}$ [27-32]. Iron can be present in $\mathrm{ZnO}$ in the form of $\mathrm{Fe}^{2+}$ and $\mathrm{Fe}^{3+}$ ions [33-36]. It is known that the dependence of the fraction of manganese or iron ions with various valences on the manganese or iron concentration, respectively, is compli- cated [27-36]. Cobalt is mainly present as $\mathrm{Co}^{2+}$. It looks that the more possible oxidation states has the dopant, the more complex is the shape of $J_{\mathrm{s}}(c)$ curve. It is clear that if we substitute a $\mathrm{Zn}^{2+}$ ion with a $\mathrm{Co}^{2+}, \mathrm{Fe}^{2+}$ or $\mathrm{Mn}^{2+}$ ion, the amount of oxygen ions $\mathrm{O}^{2-}$ remains the same in the structure of $\mathrm{ZnO}$. If the dopant has a higher valence than $\mathrm{Zn}^{2+}$, the amount of oxygen ions $\mathrm{O}^{2-}$ should decrease to preserve the neutral charge of doped $\mathrm{ZnO}$. However, if the concentration of oxygen changes, the whole structure of the nanograined zinc oxide should change, like for example the structure and properties of titanium oxide changes by the addition of dopants with different valence [37].

We compared in $[8,9,26]$ the shape of our concentration dependencies with those observed in other published works, i.e., in samples synthesised by other methods. In the majority of cases the concentration dependencies are also non-monotonous, but depend on the topology of the GB network. Most similar to the plots shown in Figure 6 are the $J_{\mathrm{s}}(c)$ curves obtained from poreless films with equiaxial grains. If the grains are elongated or flattened, the shape of the $J_{\mathrm{s}}(c)$ curves is different. Most different look the $J_{\mathrm{S}}(c)$ curves obtained in measurements with $\mathrm{ZnO}$ samples built of dense polycrystalline spheres loosely sintered $[8,9,26]$.

\section{Increase of dopant solubility with decreasing grain size: role of grain boundaries}

The vertical dotted lines in Figure 6 show the concentrations where the solubility limit $c_{\mathrm{s}}$ of $\mathrm{Fe}, \mathrm{Mn}$ or $\mathrm{Co}$ in $\mathrm{ZnO}$ is reached. Above $c_{\mathrm{S}}$ a second phase appears in the system, and the peaks of $\mathrm{Fe}, \mathrm{Mn}$ or Co oxide become visible in the XRD patterns together with wurtzite peaks of $\mathrm{ZnO}$ (Figure 7). However, why are these solubilities so high and exceed 30 atom \%, for example, in the case of cobalt? Bates et al. [38] determined the temperature dependencies of the solubilities $c_{\mathrm{S}}$ of several elements (including $\mathrm{Fe}, \mathrm{Mn}$ and $\mathrm{Co}$ ) in a volume of zinc oxide. Those $c_{\mathrm{S}}$ values do not exceed few percent, even at high temperatures. In several micro- and nanograined materials the overall solubility exceeds the $c_{\mathrm{s}}$ value [39-44].

Already in 1957, McLean [45] proposed the idea that grain boundary segregation of a second component can change the overall solubility of this second component. If we add a second component B into lattice of a matrix A, the lattice parameter of A would change (like the increase of the lattice parameter of $\mathrm{ZnO}$ after adding cobalt atoms, Figure $7 \mathrm{a}$ [46]). If the bulk solubility limit $c_{\mathrm{sb}}$ is reached, a second phase will appear in addition to the first one, and the lattice parameter stops to change and remains constant with a further increase of the concentration of B. However, the atoms of the second component that are segregated in GBs cannot build the lattice of a second phase. As a result, the second phase would appear not at $c_{\mathrm{sb}}$ but later, at 

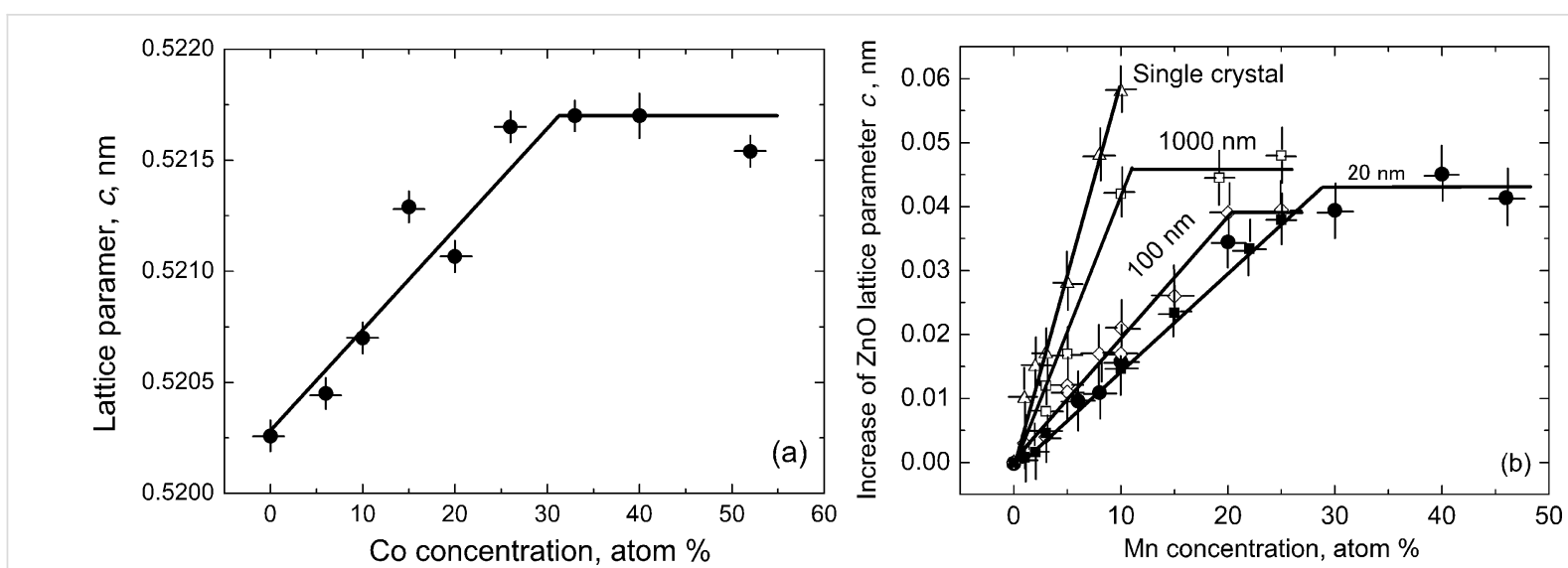

Figure 7: (a) Lattice parameter $c$ in Co-doped $\mathrm{ZnO}$ films deposited using the liquid ceramics method versus the cobalt concentration [47]. (b) Period of a $\mathrm{ZnO}$ wurtzite lattice versus the manganese concentration for different grain size [46]. Figure was replotted basing on the figures is reproduced with permission from [46,47], copyright 2008 Elsevier Ltd. (panel a) and copyright 2009 AIP Publishing (panel b).

higher concentrations of $\mathrm{B}$. This is well visible in Figure $7 \mathrm{~b}$ where the dependence of $\mathrm{ZnO}$ lattice parameter is shown for different grain sizes and Mn contents [26,47]. The steepest curve is for the single crystal. The $c_{\mathrm{sb}}$ value for $\mathrm{Mn}$ in $\mathrm{ZnO}$ lattice is only about 7 atom $\% \mathrm{Mn}$. In this case Mn atoms only substitute $\mathrm{Zn}$ atoms at the wurtzite lattice sites. If we have GBs in the sample, each new Mn atom has a choice, where to substitute $\mathrm{Zn}$, in the crystalline wurtzite lattice or in a GB. Thus, the curve for a grain size of $1000 \mathrm{~nm}$ is less steep and $c_{\mathrm{S}}$ is reached at 10 atom $\% \mathrm{Mn}$. With decreasing grain size and increasing specific GB area $s_{\mathrm{GB}}$ the solubility $c_{\mathrm{s}}$ limit increases further. Thus, $c_{\mathrm{S}}=20$ atom $\% \mathrm{Mn}$ for a grain size of $100 \mathrm{~nm}$ and $c_{\mathrm{S}}=$ 28 atom $\% \mathrm{Mn}$ for a grain size of $20 \mathrm{~nm}$ (Figure 7b). We see how drastically the solubility of Co and Mn increases with decreasing grain size and increasing specific GB area $s_{\mathrm{GB}}$.

The full dependencies of the lattice parameters on the dopant concentration are measured rather seldom [26,47]. However, the hundreds of papers on the ferromagnetic behaviour of $\mathrm{ZnO}$ give us an extremely rich source for analysing how the dopant solubility depends on the grain size. It is because when searching for ferromagnetic $\mathrm{ZnO}$, the experimentalists had to be sure that the ferromagnetic signal comes from a doped wurtzite $\mathrm{ZnO}$ and not from a (possibly ferromagnetic) second phase. Therefore, data on the presence or absence of a second phase are usually present in such publications. Quite frequently the grain size is also given (in other case it is possible to estimate the grain size from TEM micrographs or the width of XRD peaks). The temperature $T$ of synthesis or the last thermal treatment can also be determined from the publications (such as for the construction of Figure 1).

If we separate the data points for different grain sizes into different plots, $c_{\mathrm{s}}(T)$ curves can be drawn for each grain size interval. Such plots for nickel-doped zinc oxide are shown in Figure 8a-d [6] and for iron-doped zinc oxide in Figure 8e,f [12]. Similar solubility lines for different values of grain size are shown in Figure 9 for manganese-doped [16] and cobaltdoped [47] $\mathrm{ZnO}$ polycrystals. In Figure 9 the experimental points are omitted for simplicity, and only the solubility limit lines are displayed. The full plots with all points and respective list of references can be found in [46,47]. It is well visible how drastically the solubility increases with decreasing grain size. Namely, $\mathrm{ZnO}$ polycrystals with grain sizes of $20 \mathrm{~nm}$ and below can dilute dozens of atomic per cent of "magnetic atoms" without any sign of peaks of a second phase in the XRD patterns. The loosely sintered (nano)powders contain less GBs, the main defects are free surfaces. In such samples the overall solubility also increases, but now so drastically as in poreless polycrystals $[46,47]$.

Can the monolayer grain boundary or surface segregation ensure such a high increase of solubility? We estimated the thickness of the segregation layer for polycrystals with grain boundaries and with free surfaces [46,47]. It appeared that the GB contains more than 10 monolayers of $\mathrm{Mn}$ or Co [46,47]. Moreover, the GB input in the total Mn or Co concentration increases with decreasing grain size. The free surfaces are also enriched by "magnetic atoms", but the thickness of enriched surface layers is only half to about a third of that in GBs. Can we observe these layers directly, using TEM?

Figure 10 shows the bright-field HREM micrographs for two zinc oxide films doped with 10 (Figure 10a) and 15 atom \% Mn (Figure 10b) [48]. In both micrographs the $\mathrm{ZnO}$ nanograins are visible. They have a lattice with wurtzite structure (see the inset A with Fourier transform from crystalline area). Between crystalline $\mathrm{ZnO}$ nanograins the amorphous intercrystalline layers 

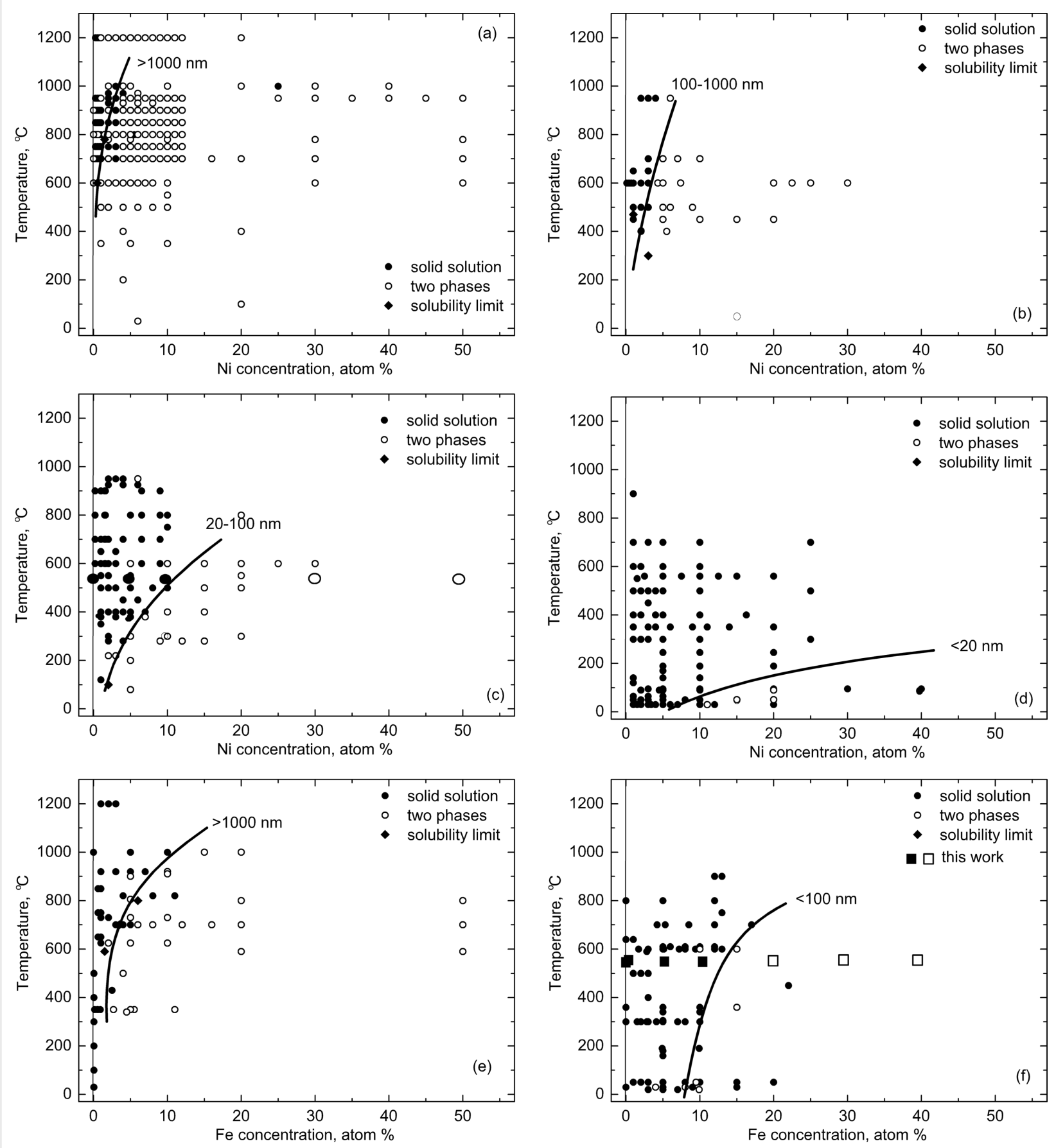

Figure 8: (a-d) Solubility limit of nickel in zinc oxide polycrystals with grain sizes (a) larger than 1000, (b) between 1000 and $100 \mathrm{~nm}$, (c) between 20 and $100 \mathrm{~nm}$, and (d) smaller than $20 \mathrm{~nm}$ [6]. (e,f) Solubility limit of iron in zinc oxide polycrystals with grain sizes (e) larger than 1000 and (f) smaller than $100 \mathrm{~nm}$ [12]. The filled and open symbols correspond to one- and two-phase samples, respectively. Diamonds mark the solubility limit. Replotted based on figures reproduced with permission from [6,12], copyright 2015 Institute of Problems of Mechanical Engineering, Russian Academy of Sciences (PME RAS, "Advanced Study Center" Co. Ltd, panels a-d) and copyright 2014 Springer Science+Business Media New York (panels e,f).

can be seen. The inset B shows the Fourier transform from such an amorphous intergranular area. It is easy to see that the amount of amorphous phase in $\mathrm{ZnO} / \mathrm{ZnO}$ GBs increases with increasing manganese content. Thus, in the alloy with 10 atom $\% \mathrm{Mn}$ the amorphous layers are visible between crys- talline $\mathrm{ZnO}$ nanograins. In the alloy with 15 atom \% Mn the crystalline $\mathrm{ZnO}$ nanograins are completely surrounded by amorphous layers. Such thick GB layers, indeed, correspond to the estimations made in $[46,47]$. However, one can find such synthesis conditions for nanograined $\mathrm{ZnO}$ for which, even in the 

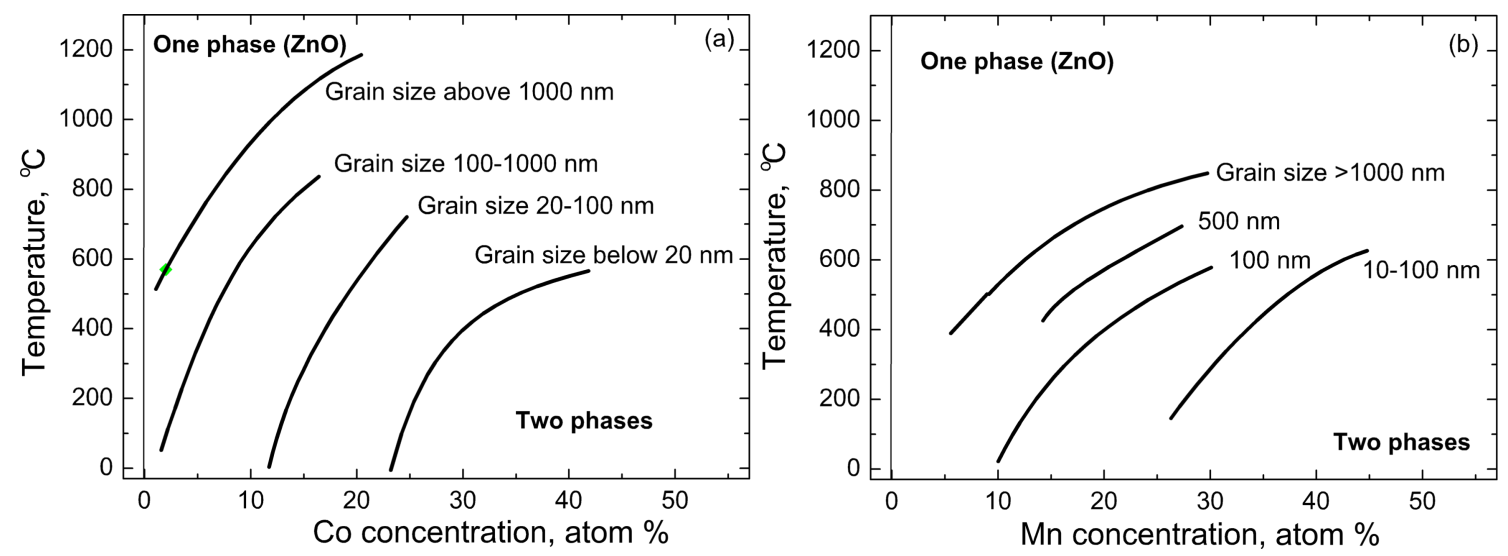

Figure 9: Solubility limit of (a) cobalt [47] and (b) manganese [46] in zinc oxide polycrystals with various grain sizes. Replotted based on figures reproduced with permission from [46,47], copyright 2008, 2009 Elsevier Ltd.
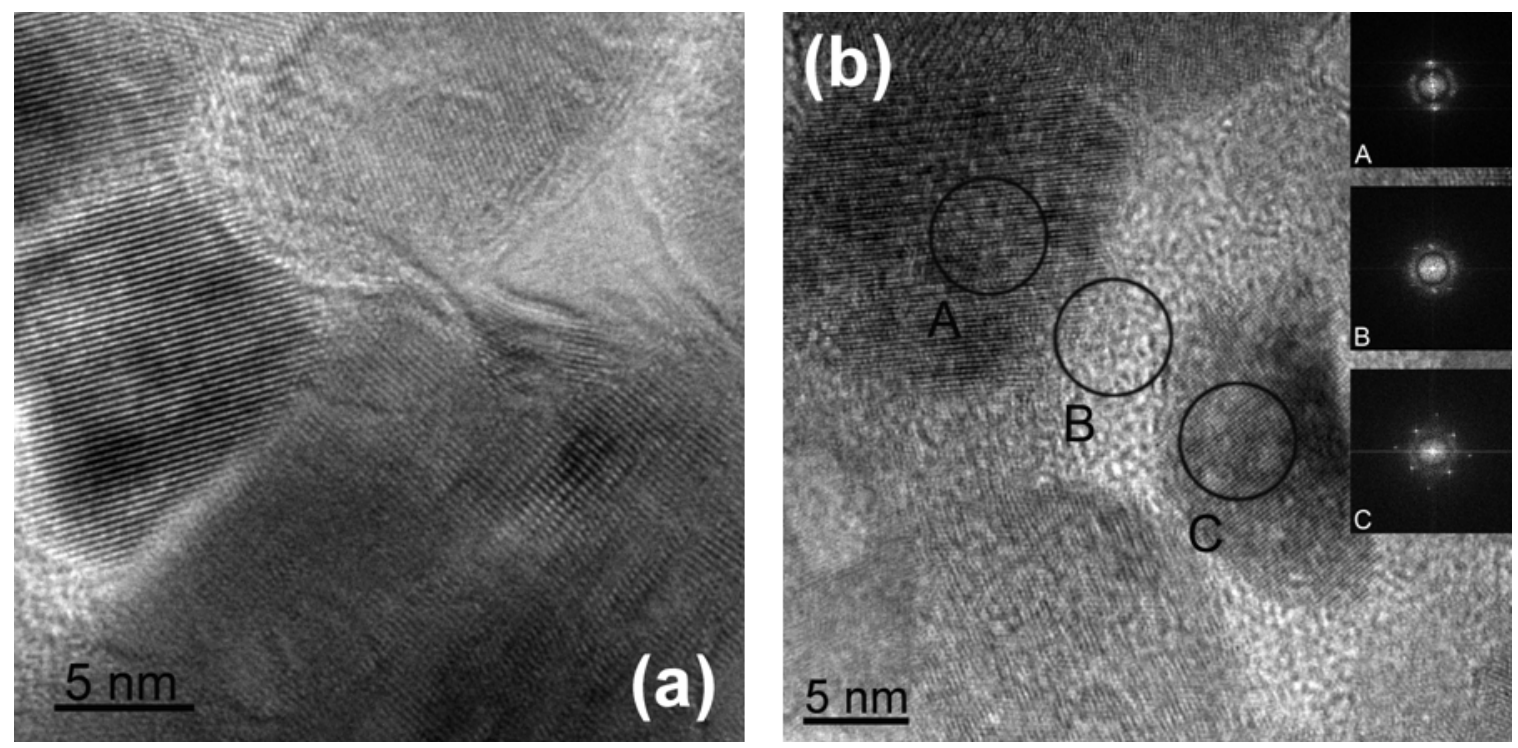

Figure 10: Bright-field HREM micrographs [48] for zinc oxide films doped with (a) 10 atom \% Mn and (b) 15 atom \% Mn. The insets show the Fourier transforms for amorphous and crystalline areas marked by letters A, B, C. Reproduced with permission from from [48], copyright 2010 Science+Business Media New York for Pleiades Publishing Inc.

case of very small grains below the threshold value (Figure 1), the sample will not have ferromagnetic properties $[45,46]$. The magnetic properties depend critically on the texture of films and the structure of amorphous GB layers [49,50]. Thus, the condition $s_{\mathrm{GB}}>s_{\mathrm{th}}$ is necessary but not sufficient for ferromagnetism of undoped $\mathrm{ZnO}$. One needs also a certain texture and structure of amorphous intercrystallite layers.

The morphology and mutual arrangement of amorphous intergranular layers and nanocrystals recalls the structures appearing in case of grain boundary wetting $[51,52]$. In particular, the approaches developed for the description of so-called GB complexions or intergranular films (IGFs) can be very effective in the future for the explanation and prediction of GB phenomena leading to the ferromagnetic behaviour in the nanograined semiconducting oxides [53-64]. The amorphous intergranular layers appear also in nanograined alloys obtained by the severe plastic deformation $[65,66]$.

\section{Conclusion}

In summary, we observed that, contrary to the prediction of Dietl et al. [1], the doping of bulk $\mathrm{ZnO}$ with $\mathrm{Mn}, \mathrm{Co}, \mathrm{Fe}$ or $\mathrm{Ni}$ does not make it ferromagnetic. On the other hand, nanograined $\mathrm{ZnO}$ becomes ferromagnetic even without doping. The presence of grain boundaries is the essential and necessary condition for the FM behavior of pure $\mathrm{ZnO}$. The specific area of GBs 
$s_{\mathrm{GB}}$ has to exceed a certain critical or threshold value $s_{\mathrm{th}}$. However, the presence of grain boundaries with $s_{\mathrm{GB}}>s_{\text {th }}$ is not a sufficient condition for ferromagnetism of undoped $\mathrm{ZnO}$. A certain texture and structure of amorphous intercrystalline layers is necessary. Nevertheless, the key role of GBs in the ferromagnetic behaviour of $\mathrm{ZnO}$ is proven by LE- $\mu$ SR. Modelling with molecular dynamics combined with density functional theory calculations permitted to find ferromagnetically coupled electron states in $\mathrm{ZnO}$ GBs.

The doping of $\mathrm{ZnO}$ with $\mathrm{Mn}, \mathrm{Co}, \mathrm{Fe}$ or $\mathrm{Ni}$, indeed, facilitates the transition into a ferromagnetic state and decreases the respective threshold values $s_{\text {th }}$. Also, the addition of few tenths of atom percent of $\mathrm{Mn}, \mathrm{Co}, \mathrm{Fe}$ or Ni drastically increases the saturation magnetization $J_{\mathrm{s}} . J_{\mathrm{s}}$ changes non-monotonously with further increase of the dopant content $c$. The number of minima and maxima of the $J_{\mathrm{s}}(c)$ curves correlates with number of valence states of dopants. Most probably, it is due to the change of oxygen content in GBs driven by the condition of electrical neutrality. The drastic increase of the total solubility of dopants in $\mathrm{ZnO}$ with decreasing grain size has been also observed. It is explained by the multilayer GB segregation.

\section{Acknowledgements}

Authors thank the Russian Foundation for Basic Research (grants 15-03-04220, 15-53-06008 and 15-33-70051), Deutsche Forschungsgemeinschaft, Ministry of Education and Science of the Russian Federation (Increase Competitiveness Program of NUST «MISiS» and project 14.B25.31.0018 from ISSP RAS), programme "New Materials" of Russian Academy of Sciences for financial support.

\section{References}

1. Dietl, T.; Ohno, H.; Matsukura, F.; Cibert, J.; Ferrand, D. Science 2000, 287, 1019-1022. doi:10.1126/science.287.5455.1019

2. Sato, K.; Katayama-Yoshida, H. Semicond. Sci. Technol. 2002, 17, 367-376. doi:10.1088/0268-1242/17/4/309

3. Gupta, T. K. J. Am. Ceram. Soc. 1990, 73, 1817-1840. doi:10.1111/j.1151-2916.1990.tb05232.x

4. Onreabroy, W.; Sirikulrat, N.; Brown, A. P.; Hammond, C.; Milne, S. J. Solid State Ionics 2006, 177, 411-420. doi:10.1016/j.ssi.2005.10.032

5. Dietl, T. Nat. Mater. 2010, 9, 965-974. doi:10.1038/NMAT2898

6. Straumal, B. B.; Mazilkin, A. A.; Protasova, S. G.; Stakhanova, S. V.; Straumal, P. B.; Bulatov, M. F.; Schütz, G.; Tietze, T.; Goering, E.; Baretzky, B. Rev. Adv. Mater. Sci. 2015, 41, 61-71.

7. Straumal, B. B.; Mazilkin, A. A.; Protasova, S. G.; Myatiev, A. A.; Straumal, P. B.; Schütz, G.; van Aken, P. A.; Goering, E.; Baretzky, B. Phys. Rev. B 2009, 79, 205206. doi:10.1103/PhysRevB.79.205206

8. Straumal, B. B.; Mazilkin, A. A.; Protasova, S. G.; Straumal, P. B.; Myatiev, A. A.; Schütz, G.; Goering, E.; Tietze, T.; Baretzky, B. Philos. Mag. 2013, 93, 1371-1383. doi:10.1080/14786435.2012.736693
9. Straumal, B. B.; Protasova, S. G.; Mazilkin, A. A.; Straumal, P. B.; Schütz, G.; Tietze, T.; Goering, E.; Baretzky, B. Beilstein J. Nanotechnol. 2013, 4, 361-369. doi:10.3762/bjnano.4.42

10. Straumal, B. B.; Mazilkin, A. A.; Protasova, S. G.; Straumal, P. B.; Myatiev, A. A.; Schütz, G.; Goering, E.; Baretzky, B. Phys. Met. Metallogr. 2012, 113, 1244-1256. doi:10.1134/S0031918X12130030

11. Straumal, B. B.; Protasova, S. G.; Mazilkin, A. A.; Schütz, G.; Goering, E.; Baretzky, B.; Straumal, P. B. JETP Lett. 2013, 97, 367-377. doi:10.1134/S0021364013060143

12. Protasova, S. G.; Straumal, B. B.; Mazilkin, A. A.; Stakhanova, S. V.; Straumal, P. B.; Baretzky, B. J. Mater. Sci. 2014, 49, 4490-4498. doi:10.1007/s10853-014-8146-y

13. Tietze, T.; Audehm, P.; Chen, Y.-C.; Schütz, G.; Straumal, B. B.; Protasova, S. G.; Mazilkin, A. A.; Straumal, P. B.; Prokscha, T.; Luetkens, H.; Salman, Z.; Suter, A.; Baretzky, B.; Fink, K.; Wenzel, W.; Danilov, D.; Goering, E. Sci. Rep. 2015, 5, 8871. doi:10.1038/srep08871

14. Watanabe, T. Mater. Sci. Forum 1997, 243-245, 21-30. doi:10.4028/www.scientific.net/msf.243-245.21

15. Gleiter, H.; Chalmers, B. High-Angle Grain Boundaries; Pergamon Press: Oxford, New York, Toronto, Sydney, Braunschweig, 1972.

16. Hosford, W. F. Materials Science: An Intermediate Text; Cambridge Univ. Press: Cambridge, UK, 2006. doi:10.1017/CBO9780511618345

17. Lábár, J. L. Microsc. Microanal. 2008, 14, 287-295. doi:10.1017/S1431927608080380

18. Wang, D. F.; Park, S. Y.; Lee, H. W.; Lee, Y. S.; Lam, V. D.; Lee, Y. P. Phys. Status Solidi A 2007, 204, 4029-4032. doi:10.1002/pssa.200777334

19. Gopalakrishnan, N.; Elanchezhiyan, J.; Bhuvana, K. P.; Balasubramanian, T. Scr. Mater. 2008, 58, 930-933. doi:10.1016/j.scriptamat.2008.01.020

20. Yaouanc, A.; Dalmas de Réotier, P. Muon Spin Rotation, Relaxation and Resonance; Oxford Science Publications: Oxford, UK, 2011.

21. Dalmas de Réotier, P.; Yaouanc, A. J. Phys.: Condens. Matter 1997, 9 , 9113-9166. doi:10.1088/0953-8984/9/43/002

22. Morenzoni, E.; Prokscha, T.; Suter, A.; Luetkens, H.; Khasanov, R. J. Phys.: Condens. Matter 2004, 16, S4583. doi:10.1088/0953-8984/16/40/010

23. Prokscha, T.; Morenzoni, E.; Deiters, K.; Foroughi, F.; George, D.; Kobler, R.; Suter, A.; Vrankovic, V.

Nucl. Instrum. Methods Phys. Res., Sect. A 2008, 595, 317-331. doi:10.1016/j.nima.2008.07.081

24. Blundell, S. J. Contemp. Phys. 1999, 40, 175-192. doi:10.1080/001075199181521

25. Suter, A.; Wojek, B. M. Phys. Procedia 2012, 30, 69-73. doi:10.1016/j.phpro.2012.04.042

26. Straumal, B. B.; Protasova, S. G.; Mazilkin, A. A.; Myatiev, A. A.; Straumal, P. B.; Schütz, G.; Goering, E.; Baretzky, B. J. Appl. Phys. 2010, 108, 073923. doi:10.1063/1.3486044

27. Cong, C. J.; Zhang, K. L. Phys. Status Solidi A 2006, 243, 2764-2771. doi:10.1002/pssb.200642258

28. Thakur, P.; Chae, K. H.; Kim, J.-Y.; Subramanian, M.; Jayavel, R.; Asokan, K. Appl. Phys. Lett. 2007, 91, 162503. doi:10.1063/1.2794764

29. Abbamonte, P.; Venema, L.; Rusydi, A.; Sawatzky, G. A.; Logvenov, G.; Bozovic, I. Science 2002, 297, 581-584. doi:10.1126/science.1070903 
30. Pellegrin, E.; Nücker, N.; Fink, J.; Molodtsov, S. L.; Gutiérrez, A.; Navas, E.; Strebel, O.; Hu, Z.; Domke, M.; Kaindl, G.; Uchida, S.; Nakamura, Y.; Markl, J.; Klauda, M.; Saemann-Ischenko, G.; Krol, A.; Peng, J. L.; Greene, R. L. Phys. Rev. B 1993, 47, 3354-3367. doi:10.1103/PhysRevB.47.3354

31. Asokan, K.; Jan, J. C.; Rao, K. V. R.; Chiou, J. W.; Tsai, H. M.; Mookerjee, S.; Pong, W. F.; Tsai, M.-H.; Kumar, R.; Husain, S.; Srivastava, J. P. J. Phys.: Condens. Matter 2004, 16, 3791-3799. doi:10.1088/0953-8984/16/21/027

32. Guo, J.-H.; Gupta, A.; Sharma, P.; Rao, K. V.; Marcus, M. A.; Dong, C. L.; Guillen, J. M. O.; Butorin, S. M.; Mattesini, M.; Glans, P. A.; Smith, K. E.; Chang, C.; Ahuja, R. J. Phys.: Condens. Matter 2007, 19, 172202. doi:10.1088/0953-8984/19/17/172202

33. Liu, H.; Yang, J.; Zhang, Y.; Yang, L.; Wei, M.; Ding, X. J. Phys.: Condens. Matter 2009, 21, 145803. doi:10.1088/0953-8984/21/14/145803

34. Wu, P.; Saraf, G.; Lu, Y.; Hill, D. H.; Gateau, R.; Wielunski, L.; Bartynski, R. A.; Arena, D. A.; Dvorak, J.; Moodenbaugh, A.; Siegrist, T.; Raley, J. A.; Yeo, Y. K. Appl. Phys. Lett. 2006, 89, 012508. doi:10.1063/1.2213519

35. Lin, Y.; Jiang, D.; Lin, F.; Shi, W. Z.; Ma, X. M. J. Alloys Compd. 2007, 436, 30-33. doi:10.1016/j.jallcom.2006.07.011

36. Karmakar, D.; Mandal, S. K.; Kadam, R. M.; Paulose, P. L.; Rajarajan, A. K.; Nath, T. K.; Das, A. K.; Dasgupta, I.; Das, G. P. Phys. Rev. B 2007, 75, 144404. doi:10.1103/PhysRevB.75.144404

37. Yermakov, A. Ye.; Uimin, M. A.; Mysik, A. A.; Vykhodets, V. B.; Kurennykh, T. E.; Sokolov, V. I.; Gaviko, V. S.; Schegoleva, N. N.; Gruzdev, N. B. J. Magn. Magn. Mater. 2007, 310, 2102-2104. doi:10.1016/j.jmmm.2006.10.780

38. Bates, C. H.; White, W. B.; Roy, R. J. Inorg. Nucl. Chem. 1966, 28 , 397-405. doi:10.1016/0022-1902(66)80318-4

39. Trudeau, M. L.; Huot, J. Y.; Schulz, R. Appl. Phys. Lett. 1991, 58, 2764-2766. doi:10.1063/1.104779

40. Suzuki, K.; Makino, A.; Inoue, A.; Masumoto, T. J. Appl. Phys. 1991, 70, 6232-6237. doi:10.1063/1.350006

41. Heera, V.; Madhusoodanan, K. N.; Skorupa, W.; Dubois, C.; Romanus, H. J. Appl. Phys. 2006, 99, 123716. doi:10.1063/1.2208299

42. Straumal, B. B.; Dobatkin, S. V.; Rodin, A. O.; Protasova, S. G.; Mazilkin, A. A.; Goll, D.; Baretzky, B. Adv. Eng. Mater. 2011, 13, 463-469. doi:10.1002/adem.201000312

43. Lemier, C.; Weissmüller, J. Acta Mater. 2007, 55, 1241-1254. doi:10.1016/j.actamat.2006.09.030

44. Rizea, A.; Chirlesan, D.; Petot, C.; Petot-Ervas, G. Solid State lonics 2002, 146, 341-353. doi:10.1016/S0167-2738(01)01024-4

45. McLean, D. Grain Boundaries in Metals; Clarendon Press: Oxford, 1957.

46. Straumal, B. B.; Mazilkin, A. A.; Protasova, S. G.; Myatiev, A. A.; Straumal, P. B.; Baretzky, B. Acta Mater. 2008, 56, 6246-6256. doi:10.1016/j.actamat.2008.08.032

47. Straumal, B.; Baretzky, B.; Mazilkin, A.; Protasova, S.; Myatiev, A.; Straumal, P. B. J. Eur. Ceram. Soc. 2009, 29, 1963-1970. doi:10.1016/j.jeurceramsoc.2009.01.005

48. Straumal, B. B.; Myatiev, A. A.; Straumal, P. B.; Mazilkin, A. A.; Protasova, S. G.; Goering, E.; Baretzky, B. JETP Lett. 2010, 92, 396-400. doi:10.1134/S0021364010180074

49. Straumal, B. B.; Mazilkin, A. A.; Protasova, S. G.; Myatiev, A. A.; Straumal, P. B.; Goering, E.; Baretzky, B. Phys. Status Solidi B 2011, 248, 1581-1586. doi:10.1002/pssb.201001182
50. Straumal, B. B.; Mazilkin, A. A.; Protasova, S. G.; Myatiev, A. A.; Straumal, P. B.; Goering, E.; Baretzky, B. Thin Solid Films 2011, 520, 1192-1194. doi:10.1016/j.tsf.2011.04.154

51. Straumal, B. B.; Baretzky, B.; Kogtenkova, O. A.; Straumal, A. B.; Sidorenko, A. S. J. Mater. Sci. 2010, 45, 2057-2061. doi:10.1007/s10853-009-4014-6

52. Straumal, B. B.; Gust, W.; Watanabe, T. Mater. Sci. Forum 1999, 294-296, 411-414. doi:10.4028/www.scientific.net/MSF.294-296.411

53. Clarke, D. R. J. Am. Ceram. Soc. 1987, 70, 15-22. doi:10.1111/j.1151-2916.1987.tb04846.x

54. Cantwell, P. R.; Ming, T.; Dillon, S. J.; Luo, J.; Rohrer, G. S.; Harmer, M. P. Acta Mater. 2014, 62, 1-48. doi:10.1016/j.actamat.2013.07.037

55. Kaplan, W. D.; Chatain, D.; Wynblatt, P.; Carter, W. C. J. Mater. Sci. 2013, 48, 5681-5717. doi:10.1007/s10853-013-7462-y

56. Bueno, P. R.; Varela, J. A.; Longo, E. J. Eur. Ceram. Soc. 2008, 28 , 505-529. doi:10.1016/j.jeurceramsoc.2007.06.011

57. Luo, J.; Chiang, Y.-M.; Cannon, R. M. Langmuir 2005, 21, 7358-7365. doi:10.1021/la0505420

58. Luo, J.; Tang, M.; Cannon, R. M.; Carter, W. C.; Chiang, Y.-M. Mater. Sci. Eng., A 2006, 422, 19-28. doi:10.1016/j.msea.2006.01.001

59. Luo, J. Crit. Rev. Solid State Mater. Sci. 2007, 32, 67-109. doi:10.1080/10408430701364388

60. Luo, J.; Chiang, Y.-M. Annu. Rev. Mater. Res. 2008, 38, 227-249. doi:10.1146/annurev.matsci.38.060407.132431

61. Subramaniam, A.; Koch, C. T.; Cannon, R. M.; Rühle, M. Mater. Sci. Eng., A 2006, 422, 3-18. doi:10.1016/j.msea.2006.01.004

62. MacLaren, I. Ultramicroscopy 2004, 99, 103-113. doi:10.1016/j.ultramic.2003.10.002

63. Dillon, S. J.; Tang, M.; Craig Carter, W.; Harmer, M. P. Acta Mater. 2007, 55, 6208-6218. doi:10.1016/j.actamat.2007.07.029

64. Luo, J.; Cheng, H.; Asl, K. M.; Kiely, C. J.; Harmer, M. P. Science 2011, 333, 1730-1733. doi:10.1126/science.1208774

65. Straumal, B. B.; Mazilkin, A. A.; Baretzky, B. Curr. Opin. Solid State Mater. Sci. 2016, 20, 247-256. doi:10.1016/j.cossms.2016.05.006

66. Straumal, B. B.; Sauvage, X.; Baretzky, B.; Mazilkin, A. A.; Valiev, R. Z. Scr. Mater. 2014, 70, 59-62. doi:10.1016/j.scriptamat.2013.09.019

\section{License and Terms}

This is an Open Access article under the terms of the Creative Commons Attribution License (http://creativecommons.org/licenses/by/4.0), which permits unrestricted use, distribution, and reproduction in any medium, provided the original work is properly cited.

The license is subject to the Beilstein Journal of Nanotechnology terms and conditions: (http://www.beilstein-journals.org/bjnano)

The definitive version of this article is the electronic one which can be found at: $\underline{\text { doi:10.3762/bjnano.7.185 }}$ 